\title{
Partially Reversible Cerebral Atrophy and Functional Improvement in Recently Abstinent Alcoholics
}

\author{
P.L. Carlen, D.A. Wilkinson, G. Wortzman, R. Holgate
}

\begin{abstract}
CT scans. The first scan was done within 5 weeks of the last drink. The degree of measurably reversible cerebral atrophy on CT scan correlated negatively with the interval between the last drink and the first CT scan. Significantly more reversibility of cerebral atrophy was noted in those subjects claiming interscan abstinence. There were positive correlations between functional improvement scores on neurological exam and reversible cerebral atrophy measurements. Significant improvement on psychological test performance was restricted to patients tested initially within 3 weeks of the last drink. Both the CT results and the psychological test results suggest that reversible changes occur soon after the cessation of drinking.
\end{abstract}

RÉSUMÉ: Des épreuves psychologiques répétées ont été administrées à cinquante-deux (52) alcooliques chroniques, abstinents depuis peu. Sur ce nombre, vingt (20) ont été soumis à des contrôles répétés par tomographie axiale cérébrale avec ordinateur, le premier contrôle ayant lieu moins de cinq (5) semaines après la dernière consommation d'alcool. Une corrélation négative a été établie entre, d'une part, l'intervalle écoulé entre la dernière consommation et la première tomographie axiale et, d'autre part, le degré d'atrophie cérébrale réversible measurable sur tomographie axiale. Un degré de réversibilité significatif plus marqué a été observé chez les sujets affirmant l'absintence entre les divers contrôles radiologiques par tomographie axiale. Des corrélations positives ont été calculées entre les scores d'amélioration fonctionnelle obtenus à l'examen neurologique et les degrés d'atrophie cérébrale réversible mesurés sur tomographie axiale. Les améliorations significatives aux épreuves de performance psychologique ont été limitées aux sujets ayant été évalués moins de trois (3) semaines après la dernière consommation. Les résultats des études par tomographie axiale et les études psychologiques suggèrent tous les deux que des changements réversibles se produisent tót après abstinence.

Can. J. Neurol. Sci. 1984; 11:441-446

Until recently, cerebral atrophy was thought to be an irreversible process, particularly since there is no evidence for neuronal reduplication in adult primates. However, there is much evidence for axonal sprouting, dendritic plasticity and regrowth in several experimental and pathological situations (Stein et al., 1974; Cotman, 1978). Also, reversible cerebral atrophy, apparent on the CT scan, has been reported in anorexia nervosa and Cushing's syndrome (Heinz et al., 1977), kwashiorkor (Dublin and Dublin, 1978), and treatment with steroids (Benston et al., 1978; Lagenstein et al., 1979).

Because of the marked clinical and psychological improvement noted in recently abstinent alcoholics over a period of weeks to months (Goldstein et al., 1968; Page and Linden, 1974; Goldman, 1982) and because alcoholism is associated with cerebral atrophy as measured by CT scan (Fox et al., 1976; Cala et al., 1978; Lee et al., 1979; Carlen et al., 1979, 1981; Bergman et al., 1980; Ron et al., 1982) we undertook a preliminary study which showed partially reversible atrophy (on CT scan) in 4 of 6 recently abstinent alcoholics (Carlen et al., 1978). This finding has been confirmed by two other groups (Artmann et al., 1981; Ron et al., 1982). We define cerebral atrophy as loss of cerebral tissue seen as measured by CT scan and do not assume that this finding implies an irreversible process. This paper deals with the results of a larger study wherein we demonstrate partially reversible cerebral morphological and functional deficits in alcoholics admitted to a treatment facility. The purposes of this study were to examine in recently abstinent alcoholics timedependent changes in cerebral morphology and cerebral function and to note if any of these changes cross-correlated.

\section{METHODS}

\section{Patient Selection}

Patients (49 males, 3 females) were recently abstinent alcoholics with a history of at least 10 years consuming more than

From the Addiction Research Foundation Clinical Institute (Drs. Carlen and Wilkinson), and Department of Medicine \& Physiology, Playfair Neuroscience Unit, Toronto Western Hospital (Dr. Carlen), and Departments of Radiology, Mount Sinai Hospital (Dr. Wortzman) and Toronto General Hospital (Dr. Holgate), University of Toronto Received December 13, 1983. Accepted in revised form August 10, 1984

Reprint requests to: Dr. P.L. Carlen, Addiction Research Foundation, Clinical Institute, 33 Russell Street. Toronto, Ontario, Canada M5S 2S1 
an average of $80 \mathrm{gm}$ ethanol/day. They were referred or selfreferred to the Addiction Research Foundation Clinical Institute, and were included in the study, provided they had no evidence of one of the following: clinically apparent liver disease (e.g. jaundice, spider nevi, hepatomegaly, ascites or persistently abnormal liver function tests), recent head trauma, history of intracranial surgery, causes of encephalopathy other than alcoholism, chronic use or abuse of psychotropic drugs including anticonvulsants or disulfiram, major psychiatric illness, and age over 69 years. Patients were examined by a neurologist and were part of a study of alcoholic cerebral atrophy (Carlen et al., 1981). All patients had signed an informed consent following full explanation of the procedures undertaken. The patients were abstinent during their stay in hospital which lasted at least 3 weeks till the CT scan and functional testing were completed. These patients were not clinically undernourished. Only patients from whom a reasonable estimate of the date of their last drink was available were studied. We differentiated those patients who maintained abstinence from those who returned to alcohol use in the interscan and interpsychological test interval on the basis of questioning the patient and his or her closest contacts.

\section{CT Scans}

Twenty patients ( 3 females, 17 males), who had their first CT scan within 5 weeks ( 35 days) from their date of last drink, who had a repeat CT scan 3 to 9 months later, and who had scans without major artifact, were studied with respect to possible reversible cerebral atrophy. These intervals were variable because at the time of the study it was not possible to obtain CT scans on short notice. No contrast was used with these CT scans which were done on an EMI Scanner (Model 1000/5) with a $160 \times 160$ matrix. Tomographic slices were $10 \mathrm{~mm}$ thick. Measurements were made from film pictures by two observers blind to the sequence of the scan and the patients's identity. The measurements were converted to real head size in centimeters using the size of the ring image for reference. The following measurements were made (Carlen et al., 1981):

$\mathrm{V}_{1}=$ the distance between the lateral tips of the anterior horns of the lateral ventricles at the same level as $V_{2}$ (see below)

$V_{2}=$ the intercaudate width of the lateral ventricles

$\mathrm{V}_{3}=$ the width of the waist of the lateral ventricles in the first or second slice above $V_{2}$, whichever yielded the larger measurement, subtracting any intervening cerebral tissue

Sulci $=$ the sum of the widths of the eight largest cortical sulci from all supratentorial $C T$ scan cuts

$\mathrm{V}_{2}$ Sulci $=$ the sum of $\mathrm{V}_{2}$ and sulci measurements

Measurements used were the average of 2 observers (P.L.C. and D.A.W.) who have demonstrated an inter-rater reliability of $r=.90$ for these measurements from 114 scans (Carlen et al., 1981) except for $V_{3}$. The scans were measured independently without knowledge of the patient's identity or the time interval between time of the scan and the time of the last drink. The means of raters' scores constituted each patient's scores. The ventricular measurements of $V_{1}$ and $V_{3}$, based on a previous study (Carlen et al., 1981) were found to be less useful than $V_{2}$ or Sulci measurements since they correlated poorly with functional measurements and age, and therefore were not used.

\section{Functional Testing}

Patients who had their last drink within 8 weeks of the first psychological test session were studied. The repeated psycho-

Table 1: Neurologic Test Battery

\section{MENTAL}

Appearance

Time of Day

Current Date

Institution Name

Own Birthdate

Numbers Forward

Numbers Backward

Doctor's Name

Shopping List

World War II Dates

Serial Sevens

Capitals and Heads of State

Insight

Confabulation

Babcock Sentence

Scoring Method: All on scale of 0, 1, 2 (no, moderate, or marked deficit), except for nystagmus, opthalmoplegia, and primitive reflexes, which were scored 0 or 1 (present or not present)

Table 2: Differentiation between change scores of abstinent patients and those presumably drinking during the interscan interval

\begin{tabular}{lccc}
\hline & $\begin{array}{c}\text { ABSTINENT } \\
(\mathbf{N}=11)\end{array}$ & $\begin{array}{c}\text { DRINKING } \\
(\mathbf{N}=9)\end{array}$ & $\begin{array}{c}\text { CONFIDENCE } \\
\text { LEVEL }\end{array}$ \\
Age & $45.0 \pm 7.4^{*}$ & $46.1 \pm 9.5$ & N.S. \\
$\begin{array}{l}\text { Interval between last } \\
\text { drink \& first CT scan } \\
\text { (DLD) }\end{array}$ & $19.7 \pm 7.8$ & $24.9 \pm 7.8$ & N.S. \\
Interval between first & & & \\
$\quad$ \& second CT scan & $96.8 \pm 42.2$ & $104.1 \pm 41.1$ & N.S. \\
$\begin{array}{l}\Delta V_{2} \\
\% \text { change }\end{array}$ & $1.7 \pm 2.8$ & $-0.5 \pm 2.4$ & $<.05$ \\
$\Delta$ Sulci & $7.3 \pm 17.5$ & $-2.8 \pm 13.9$ & N.S. \\
$\%$ change & $5.6 \pm 8.8$ & $-0.1 \pm 7.4$ & N.S. \\
$\Delta V_{2}$ Sulci & $15.2 \pm 23.7$ & $-22.6 \pm 75.4$ & N.S. \\
$\%$ change & $7.3 \pm 10.5$ & $-.9 \pm 8.6$ & $<.05$ \\
\hline
\end{tabular}

* \pm Standard Deviation

** \% change refers to change from initial score

Table 3: Cross-correlation of $\Delta V_{2}, \Delta$ Sulci, $\Delta V_{2}$ Sulci, and DLD

\begin{tabular}{|c|c|c|c|}
\hline$\Delta \mathbf{V}_{2}$ & $\begin{array}{c}\text { DLD* } \\
-.32 \\
\text { N.S. }\end{array}$ & $\Delta \mathbf{V}_{2}$ & $\Delta$ SULCI \\
\hline$\Delta$ Sulci & $\begin{array}{c}-.49 \\
p<.03\end{array}$ & $\begin{array}{c}.54 \\
\mathrm{p}<.02\end{array}$ & \\
\hline$\Delta \mathrm{V}_{2}$ Sulci & $\begin{array}{c}-.49 \\
p<.01\end{array}$ & $\begin{array}{c}.72 \\
p<.001 \\
\end{array}$ & $\begin{array}{c}.97 \\
\mathrm{p}<.001\end{array}$ \\
\hline
\end{tabular}

${ }^{*}$ DLD refers to the interval in days between the time of last drink to the time of the first CT scan.

logical tests were the Weschler Adult Intelligence Scale (WAIS) and the Weschler Memory Scale (WMS). Form I of the WMS was used at first testing and Form II for the repeat testing.

A standardized neurological test battery (Table l) requiring less than 15 minutes was administered at weekly intervals and 
A

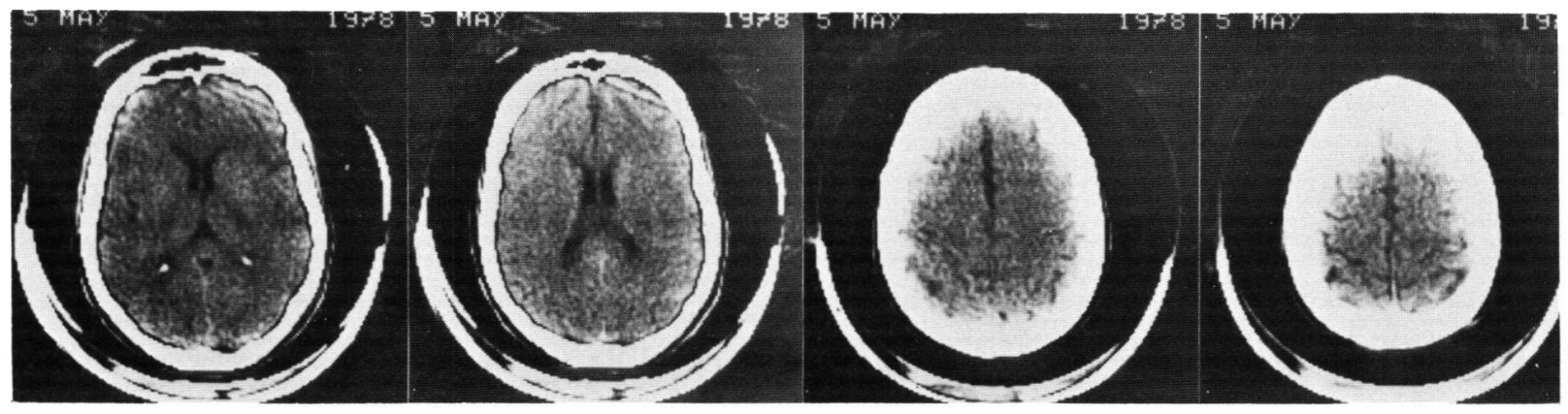

B

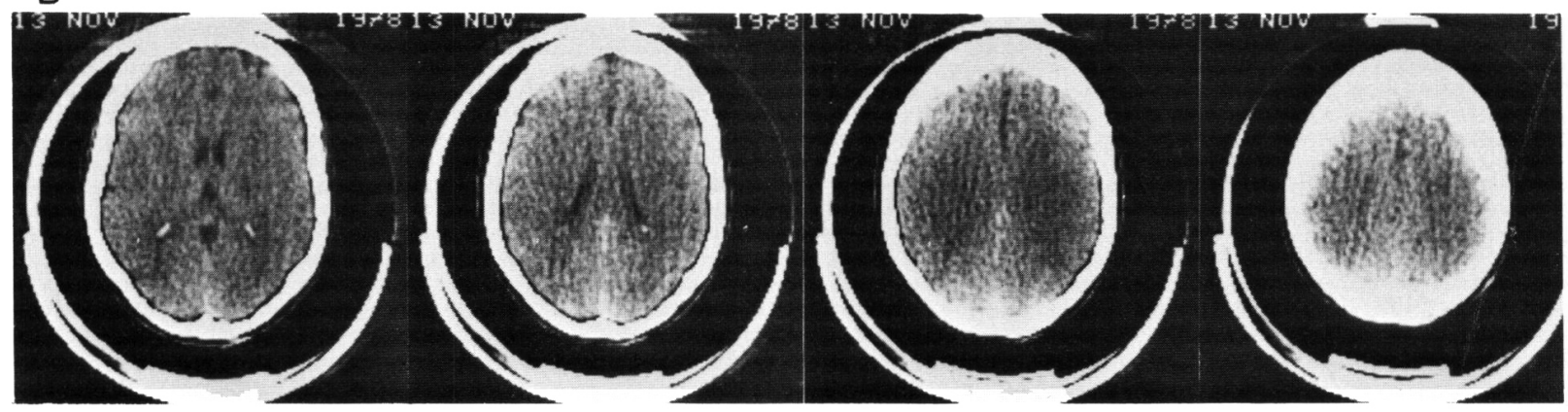

Figure 1 - Repeated CT scans of a recently abstinent 32 year old male alcoholic done 10 days $(A$, upper panel) and 115 days $(B$, lower panel) after the day of his last drink. He was reportedly abstinent during the interscan interval. Note considerably decreased cerebral cortical sulcal and ventricular atrophy in the second scan.

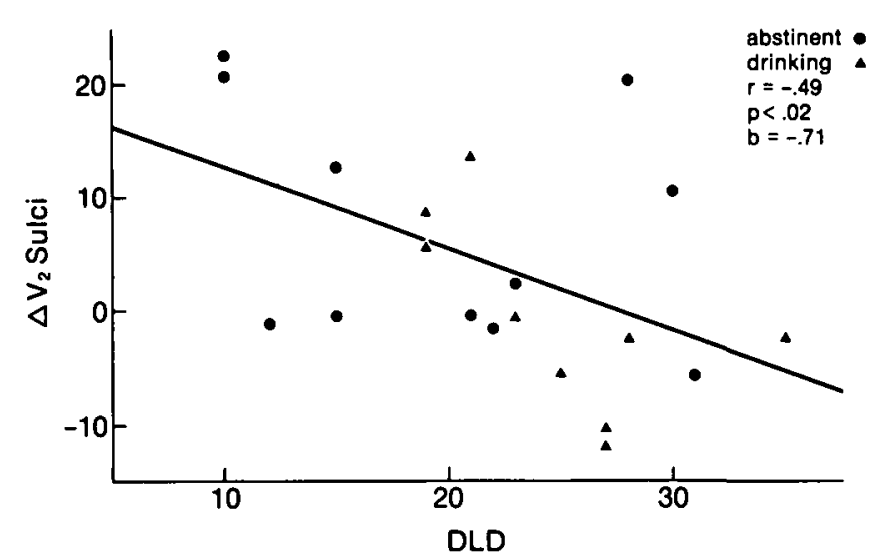

Figure 2 - Correlation of change scores of $\Delta V_{2}$ Sulci (subtracting sum of measurements of $V_{2}$ Sulci in first scan from those of the later scan in $\mathrm{mm}$.) with interval in days between date of last drink to date of the first CT scan $(D L D)$.

divided into mental and physical scores. These scores showed evidence of improvement over time with prolonged abstinence (Carlen and Wilkinson, 1980).

\section{RESULTS}

\section{Morphological Scores}

Significant changes in the CT scans of some alcoholics were observed (Figs. 1 and 2, Table 2). Although the data were quite variable, there was significantly greater change on some of the measurements in patients claiming inter-scan abstinence, despite

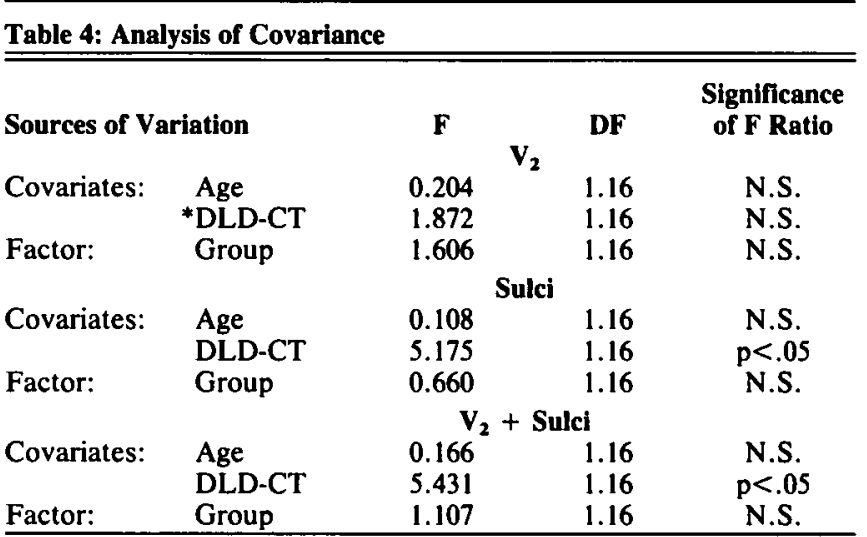

*DLD-CT refers to the interval between the date of the last drink and the date of the first CT scan.

no significant difference between the groups in mean age, interval from last drink to CT scan (DLD) or inter-scan interval (Table 2). The different change scores for individual patients correlated with each other (Table 3). $\Delta$ Sulci and $\Delta V_{2}$ Sulci were significantly correlated with the duration of abstinence before the first scan (Figure 2, Table 3). In this sample there was no significant correlation between patients age and morphological change scores. When analysis of covariance was performed with age and DLD as covariates and interscan drinking as the independent variable (abstinent or drinking groups), the only significant contribution to the variance was DLD (Table 4). 

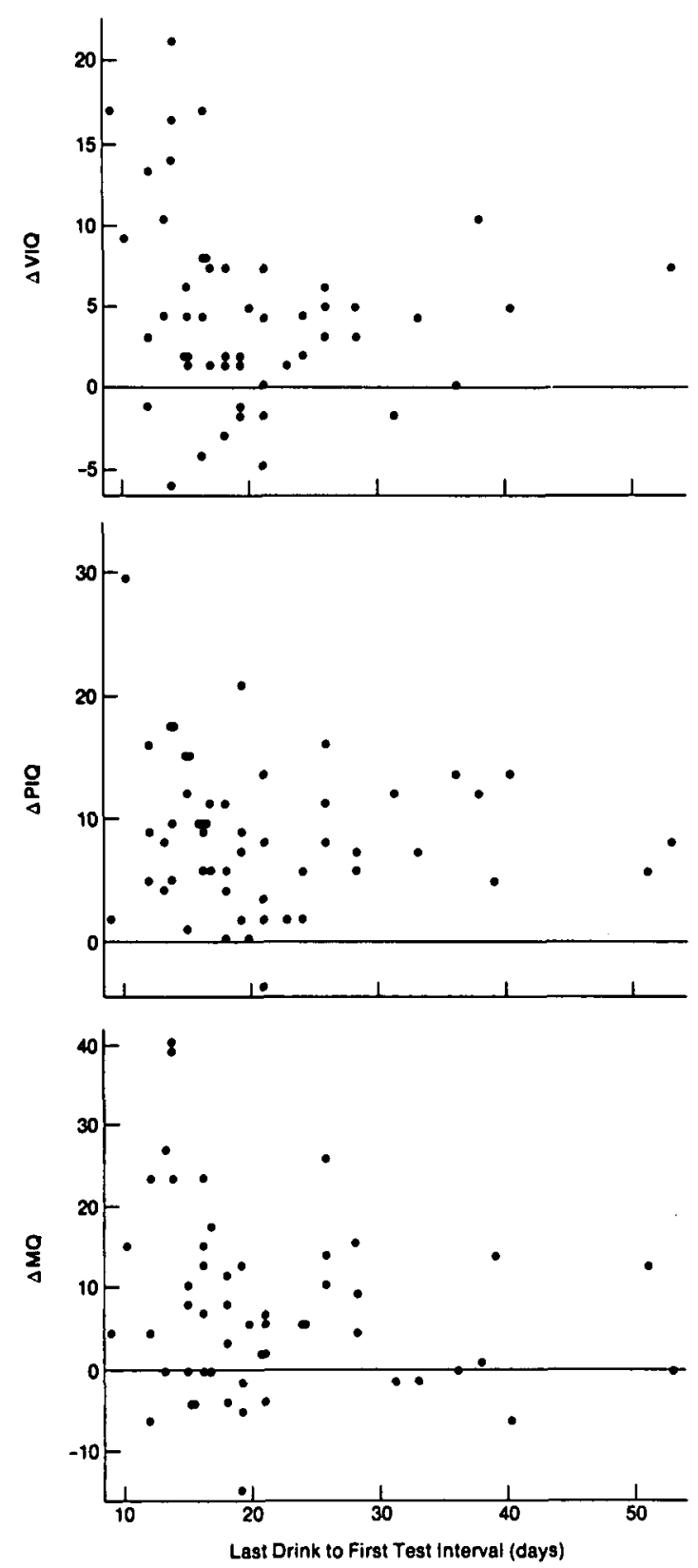

Figure 3 - Correlation of neuropsychological change scores with interval between last drink to first test session. Note increasing ordinate scales from $\triangle V I Q$ to $\triangle M Q$.

\section{Partially reversible functional deficits}

Both abstinent alcoholics and those presumed drinking during the intertest interval showed on average significantly higher IQ scores at the second neuropsychological test session (Table 5). Since there was no significant difference between the psychological change scores of abstinent compared to drinking alcoholics (although a trend towards higher change scores was noted in abstinent alcoholics), all scores were plotted together in Figure 3 which shows that the earlier the first neuropsychological testing took place after the patient's last drink, the greater was the tendency for a higher change score when subtracting the first test score from the second test score done three months later. These data suggest that "rate of recovery"
Table 5: Mean psychological change scores

ABSTINENT

SIGNIFICANCE

(2 TAILED) N

$\triangle$ VIQ $4.6 \pm 5.6$

$p<.001$

$\mathrm{p}<.001$

$\mathrm{p}<.001$

38

$\triangle \mathrm{PIQ} 8.9 \pm 6.4$

$\triangle \mathrm{MQ} 8.0 \pm 11.9$

DRINKING

$\triangle$ VIQ $3.6 \pm 6.1$

$\mathrm{p}<.045$

$\mathrm{p}<.001$

14

$\triangle \mathrm{PIQ} 7.1 \pm 5.7$

$\mathrm{p}<.001$

14

No significant differences were noted between groups in initial psychological scores, age, or change scores.

Table 6: Correlation between neurological and CT scan change scores

\begin{tabular}{lccc}
\hline \hline & $\Delta V_{2}$ & $\Delta S U L C I$ & $\Delta V_{2}$ SULCI \\
$\mathrm{N}$ & 18 & 19 & 18 \\
$\Delta$ Mental & .44 & .12 & .21 \\
& $(<.05)^{*}$ & & \\
$\Delta$ Physical & .65 & .39 & .49 \\
& $(<.005)$ & $(<.05)$ & $(<.025)$ \\
$\Delta$ Total & .58 & .25 & .35 \\
& $(<.01)$ & & \\
\hline
\end{tabular}

( ${ }^{*} 1$ Tailed $t$ Test significance in brackets)

of neuropsychological deficits in this population was greatest during approximately the first 3 weeks after the last drink. The abstinent and nonabstinent patients did not differ significantly in age or initial change scores.

The greatest change scores were seen in MQ, less in PIQ and least in VIQ (note the different ordinate scales in Figure 3). $\Delta$ PIQ correlated weakly with $\Delta$ VIQ, $(\mathrm{r}=.28, \mathrm{p} .05, \mathrm{~N}=50)$ and with $\Delta \mathrm{MQ}(\mathrm{r}=.30, \mathrm{p} .03, \mathrm{~N}=50) . \Delta \mathrm{MQ}$ correlated strongly with $\Delta$ VIQ $(r=.49, \mathrm{p} .001, \mathrm{~N}=50)$. Controlling statistically for the interval between the last drink and the first psychological testing session (DLD), the patients' age correlated positively and significantly only with $\Delta \mathrm{VIQ}(r=.51$, p.001, $\mathrm{N}=50$ ). Conversely, controlling statistically for age and correlating DLD with the psychological change scores, it was evident that the alcoholics who had their first psychological testing done within 21 days after their last drink tended to show greaterfunctional improvement in VIQ(N $=34, r=-.34$, p.05) and PIQ (N $=34, r=-.32, p .06)$ the earlier they were tested. No correlation was found between psychological and CT scan change scores. However, there was considerable variability between the time of the first CT scan and the first psychological test session. Repeated neurological scoring was performed in many of these patients. In most patients who had repeated CT scans, it was possible to find a neurological test session done within three days of the first CT scan and another approximately one month later. When the neurological change scores were correlated with the atrophy change scores, some positive correlations appeared (Table 6), particularly with the physical part of the neurological exam. The subtests (Table 1) which significantly discriminated between those who showed reversible $\mathrm{CT}$ scan atrophy and those who did not were as follows, using I-tailed $t$ tests: broad-based gait (p.025) and tandem gait (p.005) for all of $\Delta V_{2}$ Sulci and $\Delta V_{2}$ Sulci 
measurements, numbers backwards (p.025) and muscle weakness (p0.01) for $\Delta V_{2}$. The following subtests showed a change of 1 point or more over the course of the study in over $50 \%$; of the patients: current date, institution name, numbers forward, serial sevens, and Babcock sentence in the mental part of the examination; broad-based gait, tandem gait, dysmetria, resting tremor, and muscle weakness in the physical part of the neurological.

\section{Discussion}

These data indicate that at least some chronic alcoholics who are abstinent for the duration of an admission to a treatment facility show clear functional and morphological evidence of improvement. From Figure 2, it is evident that $12 / 20$ patients showed a measureable decrease in cerebral atrophy subtracting the sum of all atrophy measurements $\left(\Delta V_{2}\right.$ Sulci) taken from the second CT scan minus the first CT scan measures. The maximum negative values were -10 and $-11 \mathrm{~mm}$, both in alcoholics who had not maintained abstinence in the interscan interval. Four of the 8 patients with negative change scores were reportedly drinking during the interscan interval. There were $5 / 20$ patients with change scores greater than $+11 \mathrm{~mm}$ (i.e.their positive change scores were greater than the absolute value of the greatest negative change score) and only one of these gave a history of interscan drinking. The higher positive CT scan change scores from patients who were abstinent in the interscan interval compared to those who were reportedly drinking (Table 2) suggests that continued drinking tends to prevent reversibility of cerebral atrophy. Other authors have noted reversible cerebral atrophy in recently abstinent chronic alcoholics (Artmann et al., 1981; Ron et al., 1982).

The variability in scores is unlikely due to inter-rater error since they correlated at greater than $r=.90$ (Carlen et al., 1981). Variations in the head position at the time of different scans in the same patient could also induce measurement errors. The relationship to DLD is most surely partially obscured because of the unreliability of the drinking histories. In spite of these inconsistencies, there was a significant relationship between the interval between the last drink and the first CT scan, and the degree of reversible cerebral atrophy (Tables 3 and 4).

The neurological scores were done within 3 days or less of the first CT scan. Significant correlations were noted between neurological change scores and the CT scan change scores (Table 6) with memory and gait subtests mainly differentiating between those who showed reversible cerebral atrophy measurements and those who did not. This suggests a possible relationship between cerebral functional and morphological recovery. A long-term study more tightly controlling the interval between CT scan, duration of abstinence and functional testing is presently underway to assess this relationship.

In a recent review of the literature Bird (1982) concluded that these studies with carefully assessed and graded subjects showed significant relationships between the degree of measured atrophy on CT scan and cognitive deficits, as we noted in this sample previously (Carlen et al., 1981). However, there were no significant correlations between morphological change scores and psychological change scores in this study of reversibility. One possible reason is that there was considerable variability in the interval between the first psychological test session and the first CT scan ( $x \pm S D=7 \pm 6$ days) due to the difficulty in obtaining immediate access to the scanner. Since the initial period after the last drink is when most psychological and morphological changes seem to occur (Figures 2 and 3) this variability may have obscured any correlation. An alternative interpretation, based on the correlation of neurological scores with improvement, is that the reversible changes reflect resolution of the amnesic component of alcoholic brain syndrome. We have previously shown that the amnesic syndrome seems to resolve independently of other aspects of alcoholic encephalopathy (Wilkinson and Carlen, 1983).

The psychological change scores are significant in both abstinent and non-abstinent alcoholics, but are not beyond the range of scores seen for $\Delta$ PIQ in a sample of 76 young male university students taken 2 and 4 months after the first testing (Catron and Thompson, 1979). The university students were presumably not chronic alcoholics and had above average IQs. Their change scores should probably reflect a maximum practice or retest effect. The fact that our alcoholic population had a higher average mean change score suggests that processes other than just practice effect are contributing to the measured neuropsychological recovery. Other investigators (Goldstein et al., 1968; Page and Linden, 1974; Goldman, 1982) have also measured neuropsychological recovery in abstinent alcoholics controlling for practice effect. On the basis of evoked potential studies, it has been suggested by Porjesz and Begleiter (1981) that CNS hyperexciteability, which is part of the alcohol withdrawal syndrome, is present in chronic alcoholics for up to 3 weeks following the onset of abstinence. Hence the greater psychological change scores noted with patients tested soon after their last drink could in part reflect recovery from the alcoholic withdrawal syndrome, which is presumably a biochemical disorder (Victor, 1973). The measurably decreased morphological abnormalities occurring in the same time frame suggests that the functional recovery could involve morphological as well as biochemical elements. As well, since functional improvement can continue over months (Jenkins and Parsons, 1979) it seems likely that at least some of the improvement noted during the first month is related to recovery independent of the withdrawal syndrome. This hypothesis is strengthened by the finding that non-dependent problem drinkers who do not undergo a withdrawal syndrome, also show functional improvement in the first month of abstinence (Wilkinson and Sanchez-Craig, 1981).

Both EEG (Zilm et al., 1980; Carlen, 1982) and evoked potential studies (Porjesz and Begleiter, 1981) have shown significant electrophysiological evidence of recovery in recently abstinent alcoholics. The biological basis for this recovery is not known. Biochemical factors probably play a significant role. Victor (1973) described a hypomagnesmia in acute alcohol withdrawal which resolved over several days. Carlen et al. (1980) described a long-term cerebrospinal fluid acidosis which lasted weeks in recently abstinent alcoholics. Noble and Tewari (1973) showed that chronic ethanol ingestion in mice produced a $50 \%$ reduction in brain protein synthesis. Two weeks after alcohol withdrawal, they measured relatively increased protein synthesis.

We hypothesized that the partially reversible cerebral atrophy seen in some recently abstinent alcoholics on CT scan is due in part to increased axonal arborization and dendritic regrowth (Carlen et al., 1978; Carlen et al., 1979; Carlen and Wilkinson, 1980; Carlen, 1982). Brain rehydration or remyelination, both of which would be associated with decreased cerebral density 
measured from later CT scans, are also possible mechanisms to explain the reversible changes. Chronic alcoholics' brain density has been measured to be less than age-matched controls (Golden et al., 1981). Preliminary data of Penn et al. (unpublished observations) shows increased density in the later CT scan of 4 recently abstinent and functionally improved alcoholics.

There is much evidence that axonal regrowth or sprouting can occur in the adult nervous system following specific focal lesions (Cotman, 1978). A decrease in dendritic spines of visual cortical pyramidal cells in hypothyroid rats was demonstrated to reverse with treatment (Ruiz-Marcos et al., 1980). A recent Golgi study of human parahippocampal gyrus neurons gave evidence for dendritic regrowth and plasticity in normal aged human brain and not in senile dementia (Buell and Coleman, 1979). Neuronal loss and dendritic attenuation have been noted in mouse and rat brains fed ethanol diets reviewed by Walker et al. (1981). McMullen et al. (1984) have demonstrated with Golgi stains regrowth of hippocampal CAI cell basilar dendrites comparing rats fed ethanol for 5 months to rats fed ethanol for 5 months and withdrawn for 2 months. Similarly, Durand (1982) gives evidence compatible with regrowth of dentate granule cell dendrites in rats fed ethanol for 20 weeks and withdrawn for 3 weeks compared to pair-fed controls. We are not suggesting neuronal reduplication as a cause for the reversible CNS morphological abnormalities in human alcoholics, rather regrowth of axonal and dendritic arborizations upon removal of the chronic neurotoxin (ethanol and/or a metabolite) possibly accompanied by increased support tissue such as glia or blood vessels. As yet we have insufficient knowledge of the pathogenesis of alcoholic brain damage to differentiate those chronic alcoholics who will or will not show significant functional and cerebral morphological improvement with maintained abstinence.

\section{ACKNOWLEDGEMENTS}

Thanks for data analysis to Joanne Cordingley and Louise Goldhar. Manuscript preparation by Mary Cairoli. Supported in part by a grant from the National Institute on Alcohol Abuse and Alcoholism.

\section{REFERENCES}

Artmann H, Gall MV, Hacker H, Herrlick J (1981) Reversible enlargement of cerebralspinal fluid spaces in chronic alcoholics. Am J Neuroradiol 2: 23-27.

Benston J, Reza M, Winter J, Wilson G (1978) Steroids and apparent cerebral atrophy on computed tomography scans. J Comput Assist Tomogr 2: 16-23.

Bergman H, Borg S, Hindmarsh T et al (1980) Computerized tomography of the brain and neuropsychological assessment of alcoholic patients. Begleiter H (ed), Biological Effects of Alcohol, Advances in Experimental Medicine and Biology, Vol 126, New York, Plenum Press, pp 771-786.

Bird JM (1982) Computerized tomography, atrophy and dementia: a review. Prog in Neurobiol 19: 91-115.

Buell S, Coleman PD (1979) Dendritic growth in the aged human brain and failure of growth in senile dementia. Science 206: 854-856.

Cala LA, Jones B, Mastaglia FL et al (1978) Brain atrophy and intellectual impairment in heavy drinkers - a clinical, psychometric and computerized tomography study. Aust NZ J Med 8: 147-153.

Carlen PL (1982) Reversible effects of chronic alcoholism on the human central nervous system: Possible Biological Mechanisms. Wilkinson DA (ed): Cerebral Deficits in Alcoholism, Addiction Research Foundation, Toronto, pp 107-122.

Carlen PL, Kapur B, Huszar LA, Lee MA, Moddel G, Singh R, Wilkinson DA (1980) Prolonged cerebrospinal fluid acidosis in recently abstinent chronic alcoholics. Neurology (NY) 30: 956-962.

Carlen PL, Wilkinson DA (1980) Alcoholic brain damage and reversible deficits. Acta Psychiatr Scand 62 (Suppl 286) 103-118.
Carlen PL, Wilkinson DA, Holgate R, Wortzman G (1979) Computed tomography scans of alcoholics: cerebral atrophy? Science 204: 1237-1238.

Carlen PL, Wilkinson DA, Wortzman G, Holgate R, Cordingley J, Lee MA, Huszar L, Moddel G, Singh R, Kiraly L, Rankin JG (1981) Cerebral atrophy and functional deficits in alcoholics without clinically apparent liver disease. Neurology (NY) 31: 377-385.

Carlen PL, Wortzman G, Holgate RC, Wilkinson DA, Rankin JG (1978) Reversible cerebral atrophy in recently abstinent chronic alcoholics measured by computed tomography scans. Science 200: 1076-1078.

Catron DW, Thompson CC (1979) Test-retest gains in WAIS scores after four retest intervals. J Clin Psychol 35: 352-357.

Cotman CW (1978) Neuronal Plasticity, Raven Press, New York.

Dublin AB, Dublin WA (1978) Cerebral pseudoatrophy and computed tomography: two illustrative case reports. Surg Neurol 10: 209-212.

Durand D (1982) Alcohol-Induced brain damage: Morphology and physiology in the hippocampus in-vitro. PhD Thesis, Department of Biomedical Engineering, University of Toronto.

Fox JH, Ramsey RG, Huckman MS et al (1976) Cerebral ventricular enlargement: Chronic alcoholics examined by computerized tomography. JAMA 236: 365-368.

Golden CJ, Grabler B, Blose I, Berg R, Coffman J, Bloch S (1981) Difference in brain densities between chronic alcoholics and normal control patients. Science 211: 508-510.

Goldman MS (1982) Reversibility of psychological deficits in alcoholics: The interaction of aging with alcohol. Wilkinson DA (ed): Cerebral Deficits in Alcoholism, Addiction Research Foundation, Toronto, pp 79-105.

Goldstein G, Chotlos JW, McCarthy RJ, Neuringer C (1968) Recovery from gait instability in alcoholics. J Stud Alcohol 29: 38-43.

Heath SR Jr (1942) Rail walking performance as related to mental age and etiological type among mentally retarded. Am J Psychol 55: 240-247.

Heinz ER, Martinez J, Haenggeli A (1977) Reversibility of cerebral atrophy in anorexia nervosa and Cushing's syndrome. J Comput Assist Tomogr 1(4): 415-418.

Jenkins RL and Parsons OA (1979) Recovery of cognitive abilities in male alcoholics. Alcohol Clin Exp Res 3: 181 .

Lagenstein I, Willig RP, Kuhne DC (1979) Reversible cerebral atrophy caused by corticotrophin. Lancet 1: 1246-1247.

Lee K, Moller L, Hardt F, Aksel H, Jensen E (1979) Alcohol induced brain damage and liver damage in young males. Lancet 2: 759-761.

McMullen PA, Saint-Cyr JA, Carlen PL (1984) Morphological alterations in rat $\mathrm{CA}_{1}$ hippocampal pyramidal cells resulting from chronic ethanol consumption and withdrawal. J Comp Neurol 225: 111-118.

Noble EP, Tewari S (1973) Protein and ribonucleic acid metabolism in brains of mice following chronic ethanol consumption. Sexias FA, Eggleston S (eds), Alcoholism and the Central Nervous System, New York Academy of Sciences, New York, pp 333-345.

Page RD, Linden JD (1974) "Reversible" organic brain syndrome in alcoholics: A psychometric evaluation. QJ Stud Alcohol 34: 98-107.

Porjesz B, Begleiter H (1981) Human evoked brain potentials and alcohol. Alcoholism: Clin Exper Res 5: 304-317.

Ron MA, Acker W, Shaw GK, Lishman WA (1982) Computerized tomography of the brain in chronic alcholism, a survey and followup study. Brain 105: 497-514.

Ruiz-Marcos A, Sanchez-Toscano F, Escobar Del Rey F, Morrelae De Escobar M (1980) Reversible morphological alterations of cortical neurons in juvenile and adult hypothyroidism in the rat. Brain Res 185: $91-102$.

Stein DG, Rosen JJ, Butters N (1974) Plasticity and Recovery of Function in the Central Nervous System, Academic Press, New York.

Victor M (1973) The role of hypomagnesemia and respiratory alkolosis in the genesis of alcohol-withdrawal syndrome. Ann New York Acad Sci 215: 235-248.

Walker DW, Huster WH, Abraham WC (1981) Neuroanatomical and functional deficits subsequent to chronic ethanol administration in animals. Alcoholism: Clin Exp Res 5: 267-282.

Wilkinson DA, Carlen PL (1984) Recoverability in recently abstinent alcoholics: Results of repeated neuropsychological, EEG, CT scan and neurological examinations. Presented at the 11 th Annual Meeting of the Neuropsychological Society, Mexico City, 1984 and Submitted.

Wilkinson DA, Sanchez-Craig M (1981) Relevance of brain dysfunction to treatment objectives. Behaviors 6: 253-260.

Zilm DH, Huszar LA, Carlen PL, Kaplan H, Wilkinson DA (1980) EEG correlates of the alcohol-induced organic brain syndrome in man. Clin Toxicol 16(3): 345-358. 